\title{
Epidemiological Investigation for the Incidence of Plasmodium falciparum Malaria from Tribal Areas in Koraput District of Odisha State, India
}

\author{
Marimuthu Ramar, ${ }^{1, *}$, Subash Chandra Mohanty ${ }^{2}$, Sudhansu Sekhar Sahu ${ }^{3}$, Kasinathan Gunasekaran ${ }^{3}$, \\ Purusothaman Jambulingam ${ }^{3}$ \\ ${ }^{1}$ National Institue of Malaria Research (ICMR), Field Unit, Sector-3, BHEL, Hardwar, Uttrakhand, India \\ ${ }^{2}$ National Institute of Malaria Research(ICMR), Field Unit, RLTRI Campus, Lalpur, Raipur, Chhattisgarh \\ ${ }^{3}$ Vector Control Research Centre (ICMR), Medical Complex, Indira Nagar, Puducherry, India \\ *Corresponding author: ramareri@gmail.com
}

Received September 09, 2014; Revised October 17, 2014; Accepted October 22, 2014

\begin{abstract}
Malaria is a major public health problem in India and its dynamics vary from place to place. In India malaria is complex because of vast tracts of forest with tribal settlement. Koraput, it is mainly tribe-inhabited and one of the highly endemic districts of Odisha State that contributes a considerable number of malaria cases in India. During 2009 in Kunduli CHC \%Pf, SPR and API were 100\%, 25.7 and 38.6 respectively. The \% Pf, SPR and API of Dudhari Sbub Centre in year 2010 were 100\%, 14.86 and 35.31 respectively. From 2007 onwards there was steady increase in number of $P$. falciparum cases and during 2008, the the prevalences of infection caused by the $P$. falciparum were high. In 2010 and SPR and API rose to $19.7 \%$ and 36.7\%, respectively. The results of the current study indicated a rising trend in transmission of malaria in Koraput district compared to the situation in previous report and it is opposing approach for the control of the disease by improving treatment measures with adequate knowledge in the tribe area.
\end{abstract}

Keywords: Epidemiological investigation, Plasmodium falciparum, malaria incidence, tribal area, Koraput, Odisha, India

Cite This Article: Marimuthu Ramar, Subash Chandra Mohanty, Sudhansu Sekhar Sahu, Kasinathan Gunasekaran, and Purusothaman Jambulingam, "Epidemiological Investigation for the Incidence of Plasmodium falciparum Malaria from Tribal Areas in Koraput District of Odisha State, India." American Journal of Epidemiology and Infectious Disease, vol. 2, no. 4 (2014): 109-114. doi: 10.12691/ajeid-2-4-5.

\section{Introduction}

Malaria is a major public health problem in India and its transmission dynamics differ from place to place [1]. The Orissa state on the east coast of India is endemic for malaria for decades [2]. The state with a population of $4 \%$, contributes about $43.9 \%$ of all malaria cases, $43.9 \%$ of the Plasmodium falciparum cases and $25.5 \%$ of total malaria deaths reported during 2008 [3]. Transmission of malaria is persistent in all hilltop and foothill villages [4] Malaria incidence is especially multifarious in Odisha State because of vast territory of forest with tribal arrangement. The disease is in nature distributed but remains entrenched in poor population groups particularly in hilly and forested areas characterized by high incidence and deaths due to $P$. falciparum infection [5]. Of the 30 districts of Odisha State, Koraput district is one such area with many hills and forests, accounting for $8.5 \%$ of all malaria cases, 9.4\% of $P$. falciparum malaria and $6.3 \%$ of deaths due to malaria, during 2008 [3]. Although previous studies showed that this district is hyperendemic for malaria [6]. Three billion people- almost half of the world populations are at risk of malaria infection in 109 malarious countries and territories with approximately 250 million cases and one million deaths annually. In the absence of effective control, these diseases have a major impact on public health and socio-economic development [7,8]. The principal vectors, which cause malaria in the state, are the An. culicifacies, Anopheles fluviatilis and Anopheles annularis are the three major vectors [9]. In India, reports suggest that mortality in complicated $P$. falciparum malaria in Vellore in southern state of Tamil Nadu was 7.9\%, while in Jabalpur (Madhya Pradesh) and Rourkela (Orissa) it was 25.6 and 30\% respectively [10]. In India, trials areas are diverse eco-epidemiological settings for controlling malaria transmitted by Anopheles culicifacies [11], An. fluviatilis [12], An. minimus [13] and An. dirus [14] complex mosquitoes.

In Madhya Pradesh and Chhattisgarh states have reported more than 25\% malaria cases in tribal population. The gravity of the trouble can be assessed by the fact that in Madhya Pradesh (pop 63,668,000), 19\% population of the 15 districts of state is under Enhanced Malaria Control Project (EMCP) which contribute 53\% malaria and 71.5\% $P$. falciparum cases. Similarly Chhaittisgarh has a total population of $23,070,000$ of which $41 \%$ are under EMCP, 
which contribute $91 \%$ of malaria and $96 \%$ of P.falciparum cases in the state [15]. Almost all the deaths (91\%) in Chhattisgarh were from EMCP districts. The ethnic tribal population of Chhattisgarh is one third of total population which is highest for any state in the country. Further, it is the 2nd highly malarious state in India after Orissa [16]. The annual blood examination rate (ABER) and annual parasite incidence (API) of India were 8.5 and 1.8 respectively in 2002, while the corresponding figures for Chhattisgarh were 16.22 and 10.65. Since large part of both Madhya Pradesh and Chhattisgarh are hilly, forested and inaccessible with poor communication facilities, control of malaria is logistically difficult and outbreaks are frequently recorded $[17,18]$. This paper recapitulate the results of the study on malaria prevalence carried out in Kunduli community health centre (CHC) and Dudhari Sub-Centre (SC) in Koraput district; these results could be useful for the plan of suitable site-specific malaria control approach.

\section{Methodology}

\subsection{Study Area}

The present survey was carried out during 2007 to 2011 in Kunduli (CHC) and Dudhari (SC) of the Koraput district (Figure 1). The present study district has an inhabitants of 13, 05,492 during, 2008 [19,20]. The selected CHC and SC are situated by natural boundaries of several hills and it is a tribal dominated villages. Also, it is situated on the hill slops and has various rows of streets with intersecting roads and a common road that communicates the village. A natural stream of water goes along the middle of one of the intersecting roads is a unique feature of the village. The villagers take a charm of using the flowing water in front of their houses for their daily hood purposes.

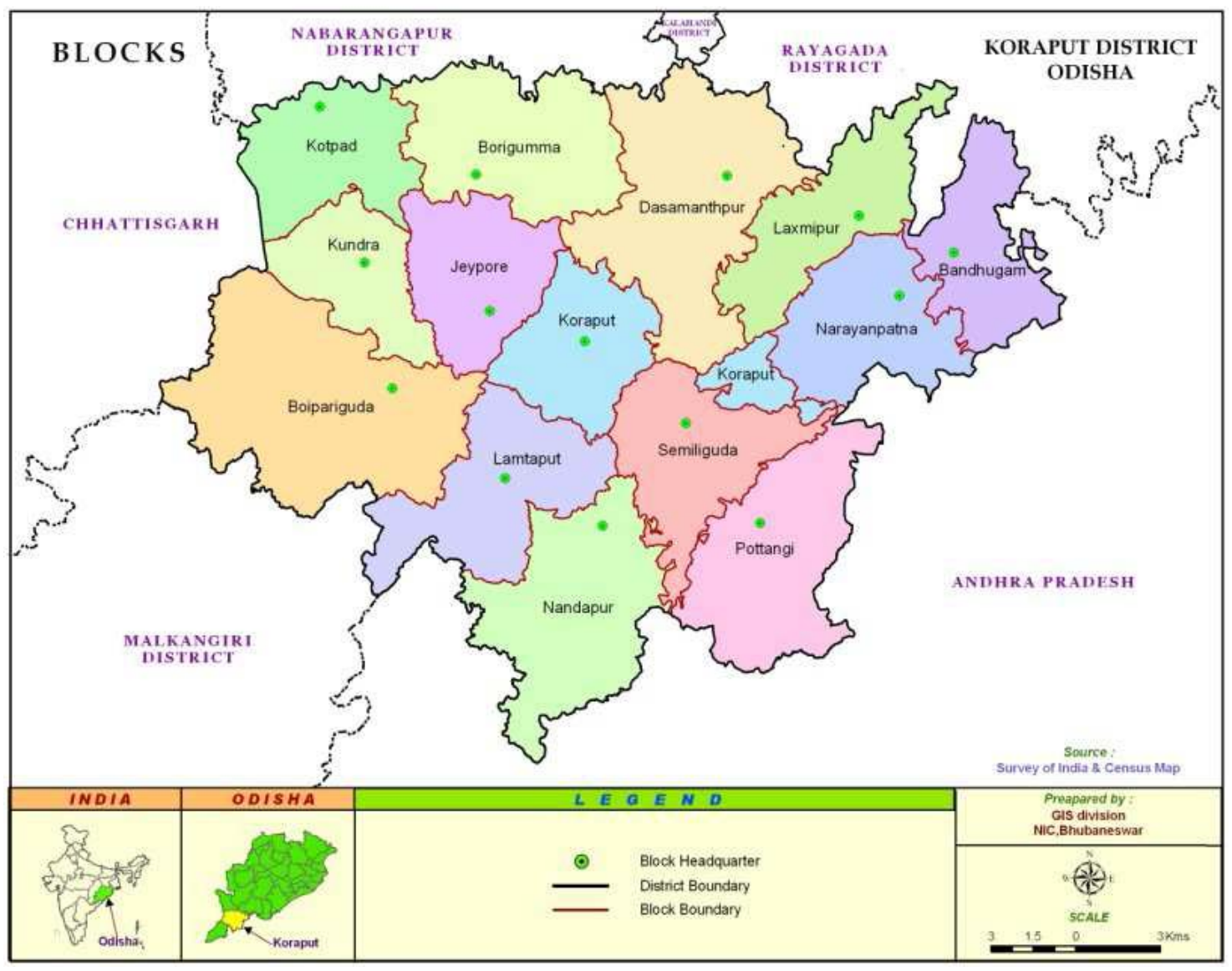

Figure 1. Map of the study district

\subsection{Topography}

The district has an area of 8,807 sq km, and is situated in the southern part of Odisha State (18013' and 19010' north latitude and 8205' and 83013' east longitude). A number of $21 \%(1,879.53 \mathrm{sq} \mathrm{km})$ of the total area is covered with forest [19]. Koraput district (Figure 1) lies on a section of the Eastern Ghats and consists of five natural divisions having mean elevation of 3.000, 2.500; 1.000 and 500 feet above the sea level. A number of mountain ranges and isolated hill rise out of these table lands. The whole tract can be divided into the following four divisions each of which can be separated by natural barriers as their respective limits.
The Geographical unit is consists of Bissam Cuttack Gunpur Rayagada \&Kashipur in the revere places of state. The whole of the region consists of two fertile valleys of the Nagavali and the Vansadhara, between ruggy mountain ranges. The 3,000 feet plateau extends from Kashipur tehsil to the border of the east Godavari district in Andhra Pradesh. It is drained westward by the Machhkund towards the Godavari valley. The two study villages the Ghataguda and the Phulobandha comes under this category. The 2,000 feet plateau covers almost the entire extent of Nabarangpur Sub divisions. It extends further to the west into Bastar and in the north into the district of Raipur. In the south it falls away by stiphyghats into the Malkangiri Tahsil. The Malkangiri Sub division 
forms the fourth natural division:There are many out standing peaks in Koraput, the most notable ones being TurriaMunda (5.244 feet) Polamakani Parbat (5,201feet) Meya Mali parbat (4,921feet), Kurmapadikonda (4,896feet) etc.

\subsection{Rivers}

In Koraput District there are many rivers and perennial streams. There are five large and important rivers two of which, the Vansadhara and the Nagavali, flow southwards into Srikakulam district and ultimately fall into the Bay of Bengal. Of the remaining three, Machkund flows westward and then southward before reaching the basin of river of Godavari. Two other important rivers are Indravati and Kolab. The natural streams of the two study villages drain water to the Kerandi river which ultimately joins with Kolabriver / the Kolab reservoir.

\subsection{Forest Area}

A large amount of the areas of Koraput District are under forest. 5,521 square miles of the District comes under forest, the forests of Koraput are of Northern tropical semi-evergreen type. There are many plants of great economic importance in the forest. Teak and Sal are found in abundance. Other predominant forest products are bamboo and a particular variety of coarse grass rising up to a height of 10 feet. In the more densely-populated areas, as in the hills to the south of Koraput, the practice of shifting cultivation repeatedly carried out over a long period has reduced the forest to an open scrub type or barren soil. The existing forest has all been under shifting cultivation. In Koraput Disttrict shifting cultivation is known as "podu", the Paraja call it Kodki. Forest area of Koraput district has come down to $21.34 \%$ of total geographical area of the district. Reckless forest cutting and deforestation quickly degraded its forest resources. Apart from it Podu cultivation by the local inhabitants further degraded its plant habitant.

\subsection{Soil}

In Koraput, red soil with small patches of late rite soil is found in the northeast and black cotton soil in the southeast. Rocks contain large deposits of Iron, Manganese, Mica and Graphite. Limestone deposits are also found abundantly.

\subsection{Agriculture}

Agriculture takes a predominate role in the district economy. Paddy is the principal crop; raggi is the next production of paddy occupied 1.0 loch hector, maize 1508 hector and Vegetable 26722 hector during khariff season of 2009-10. The Koraput region is famous for hills, forests and its tribal people. The Tribal mostly live in the hills and forests and therefore, the "Adivasis" are also called "Girijans" and the "Vanavasis". Until 1960s about the 70 per cent of the geographical areas of the region was covered by the forests; but due to several reasons a large part of the forest area has been destroyed and at present only about 24 per cent of the area has some forest cover.

\subsection{Meteorological Data}

The type of weather of the Koraput district is characterized by hot summer (March-June), rainy (JulyOctober) and cold (November-February) seasons. The monsoon usually breaks during the later part of June each year. Average annually rainfall recorded during 2007 was $2,278.0 \mathrm{~mm}$, of which $>80 \%$ occurred during July to September under the influence of the south-west monsoon. Maximum rainfall was in August. The mean minimum temperature varied between $14.0^{\circ} \mathrm{C}$ (January-February) and $27.5^{\circ} \mathrm{C}$ (April-May) and mean maximum temperature between $27.0^{\circ} \mathrm{C}$ (December) and $41.5^{\circ} \mathrm{C}$ (May) [19].

\subsection{Demographic Features}

The Koraput district, constituting more than 55\% of the district's total population, distributed in 14 CHCs (Table 1 $\&$ Table 2). The major occupation of the people is agriculture and collection of forest products. The people of the district, in general, are economically poor; their literacy rate is $35.7 \%$ against the State's $63.1 \%[19,20]$. They have immense faith in sorcery and witchcraft. The villages are scattered and the houses are built of thatched or tiled roof and mud wall. Houses are generally dark, damp and often without ventilation. Cattle sheds are adjacent to human dwellings and very often domestic animals, such as chicken and goats are also sheltered in the house.

Table 1. Koraput District at a Glance (Source: Census of Odisha State)

\begin{tabular}{|l|c|c|}
\hline Description & $\mathbf{2 0 0 1}$ & $\mathbf{2 0 1 1}$ \\
\hline Actual population & $1,180,637$ & 1376934 \\
\hline Male & 590,743 & 677,864 \\
\hline Female & 589,894 & 699,070 \\
\hline Population Growth & $14.67 \%$ & $16.63 \%$ \\
\hline Area Sq. Km & 8,807 & 8,807 \\
\hline Density/km2 & 134 & 156 \\
\hline Proportion to Orissa Population & $3.21 \%$ & $3.28 \%$ \\
\hline Sex Ratio (Per 1000) & 999 & 1031 \\
\hline Average Literacy & 35.72 & 49.87 \\
\hline Male Literacy & 47.20 & 61.29 \\
\hline Female Literacy & 24.26 & 38.92 \\
\hline Literates & 350,044 & 579,203 \\
\hline Male Literates & 231,055 & 348,447 \\
\hline Female Literates & 118,989 & 230,756 \\
\hline Population (\%) & $16.37 \%$ & $83.63 \%$ \\
\hline Total Population & 225,406 & $1,151,528$ \\
\hline Male Population & 114,442 & 563,422 \\
\hline Female Population & 110,964 & 588,106 \\
\hline Sex Ratio & 970 & 1044 \\
\hline
\end{tabular}

\subsection{Epidemiological Survey}

Epidemiological surveys were conducted in the study area during 2007-2011. Yearly epidemiological data were collected from District Health Department, CHC and SC Centre of Koraput district, Odhisa. Different parameters such as $P$. falciparum percentage ( $\mathrm{Pf} \%$ ), slide positivity rate (SPR) and annual parasite incidence (API) were calculated to assess the malaria situation. The above mentioned parameters were calculated by the following methods:

$$
\begin{aligned}
& P \text {. falciparum Rate }(\mathrm{Pf} \%) \\
= & \frac{\text { Total } P \text {. falciparumslides }}{\text { Total positive slides }} \mathrm{X} 100
\end{aligned}
$$


Slide Positive Rate (SPR)

$=\frac{\text { Total positive slides }}{\text { Total Blood slide Examined }}$ X100
Annual Parasite Incidence (API)

$=\frac{\text { Total slides found positive }}{\text { Total Population }}$ X100

Table 2. Health related indicators of Koraput District at a Glance (Courtesy: Health department of India)

\begin{tabular}{|c|c|c|c|}
\hline \multicolumn{4}{|c|}{ Health related indicators of Koraput District at a Glance } \\
\hline & Koraput & Orissa & India \\
\hline Geographical Area (Sq. Km) & 8379 & 155707 & 3287240 \\
\hline Sub-divisions & 02 & 58 & 5463 \\
\hline Tahsils & 07 & 171 & \\
\hline Blocks & 14 & 314 & 4378 \\
\hline Towns & 05 & 138 & 4378 \\
\hline Urban Bodies & 04 & 107 & 3799 \\
\hline Gram Panchayat & 226 & 6234 & 26500 \\
\hline Goverrnment Medical College & 00 & 03 & 102 \\
\hline District Headquarter Hospital & 01 & 30 & 600 \\
\hline Sub Divisional Hospital & 01 & 22 & 3342 \\
\hline Community Health Centres & $\begin{array}{c}9 \\
\text { (CHC I-4 } \\
\text { (Boipariguda, Borigumma, Kotpad \& Nandapur) } \\
\text {,CHC-II-5 } \\
\text { (Dasmanthpur, Mathalput, Pottangi, Rabanaguda, Laxmipur) }\end{array}$ & 231 & 3346 \\
\hline PHC & $\begin{array}{c}5 \\
\text { (Bandhugoan, Lamtaput, Kunduli, Kundura, Narayanpatna) }\end{array}$ & 114 & 23236 \\
\hline PHC (N) & 46 & 1164 & N/A \\
\hline Total beds & $\begin{array}{c}567 \\
\text { ( } 0.43 \text { per } 1000 \text { Population) }\end{array}$ & $\begin{array}{c}14166 \\
\text { (0.43 per } 1000 \\
\text { population) }\end{array}$ & $\begin{array}{c}0.8 \\
\text { ( per } 1000 \\
\text { Population) } \\
\end{array}$ \\
\hline No of Sub Centers & 307 ( inclusive of new ) & $\begin{array}{c}6688 \\
\text { (inclusive of new ) }\end{array}$ & 146026 \\
\hline No. of ASHAs & 1488 (In-position-1435) & & \\
\hline No. of Health Sectors & 53 & & \\
\hline LHV/UG centre & 32 & & \\
\hline No of AWCs & 2723 (In position-1624) & 41697 & 1052638 \\
\hline
\end{tabular}

\section{Results}

The summary of the data for the assessment of the endemic inference of malaria that the only one Plasmodium specie $P$. falciparum on Koraput district, CHC and SC from 2007 to 2011 is presented in Table 3, Table 4 \& Table 5. Annual results revealed that in 2011, a moderate number of malaria cases, mainly due to $P$. falciparum, were recorded (Table 4 \& Table 5). During 2009 in Kunduli CHC \%Pf, SPR and API were 100\%, 25.7 and 38.6 respectively. The \% Pf, SPR and API of Dudhari Sbub Centre in year 2010 were 100\%, 14.86 and
35.31 respectively. From 2007 onwards there was steady increase in number of $P$. falciparum cases and during 2008, the the prevalences of infection caused by the $P$. falciparum were high (Table 3). From 2007 onwards both SPR and API showed an increasing trend while death was on decline. There was further sudden increase in 2010 and SPR and API rose to $19.7 \%$ and $36.7 \%$, respectively. However, SPR showed further decline (16.1\%). In year 2011, there was a decline in number of malaria infections but the trend of SPR and API and SPR remained the same. $P$. falciparum percentage was progressively from $92.7 \%$ in 2007 to $94.8 \%$ in 2011 . This yearly change in $P$. falciparum percentage is shown in Table 5.

Table 3. Epidemiological Data of Malaria for Koraput District from 2007- 2011

\begin{tabular}{|c|c|c|c|c|c|c|c|c|}
\hline Year & Population & BSC & Positive & P.F & (\%)Pf & Death & SPR & API \\
\hline 2007 & 1307634 & 216654 & 27421 & 25431 & 92.7 & 42 & 12.6 & 20.9 \\
\hline 2008 & 1300924 & 237766 & 32761 & 30990 & 94.5 & 63 & 13.7 & 25.1 \\
\hline 2009 & 1342093 & 240374 & 39569 & 36406 & 92.0 & 31 & 16.4 & 29.4 \\
\hline 2010 & 1324161 & 246601 & 48559 & 45579 & 93.8 & 33 & 19.7 & 36.7 \\
\hline 2011 & 1335260 & 269390 & 43267 & 41038 & 94.8 & 9 & 16.1 & 32.4 \\
\hline
\end{tabular}

BSC: number of blood slides collected; Positive: malaria positive case; Pf: presence of Plasmodium falciparum; \% Pf: percentage of $P$. falciparum; SPR: slide positive rate (\%); API: annual parasite incidence.

Table 4. Epidemiological Data of Malaria for Kunduli CHC from 2007-2011

\begin{tabular}{|l|c|c|c|c|c|c|c|c|}
\hline Year & Population & BSC & Positive & P.F & (\%)Pf & Death & SPR & API \\
\hline 2007 & 67158 & 6462 & 871 & 871 & 100 & 0 & 10.3 & 12.9 \\
\hline 2008 & 65889 & 9560 & 1327 & 1327 & 100 & 4 & 13.8 & 20.1 \\
\hline 2009 & 69131 & 10355 & 2670 & 2670 & 100 & 2 & 25.7 & 38.6 \\
\hline 2010 & 69198 & 11625 & 2114 & 2104 & 99.5 & 4 & 18.2 & 30.1 \\
\hline 2011 & 79067 & 10060 & 852 & 852 & 100 & 1 & 8.47 & 10.78 \\
\hline
\end{tabular}

BSC: number of blood slides collected; Positive: malaria positive case; Pf: presence of Plasmodium falciparum; \% Pf: percentage of P. falciparum; SPR: slide positive rate (\%); API: annual parasite incidence. 
Table 5. Epidemiological Data of Malaria for Dudhari Sub-Centre from 2007-2011

\begin{tabular}{|l|c|c|c|c|c|c|c|c|}
\hline Year & Population & BSC & Positive & P.F & (\%)Pf & Death & SPR & API \\
\hline 2007 & 4391 & 512 & 85 & 85 & 100 & 0 & 16.6 & 19.36 \\
\hline 2008 & 2210 & 410 & 52 & 52 & 100 & 0 \\
\hline 2009 & 2568 & 242 & 46 & 46 & 100 & 0 & 12.68 & 23.53 \\
\hline 2010 & 2096 & 498 & 74 & 74 & 100 & 0 & 19.01 & 17.91 \\
\hline 2011 & 2046 & 545 & 39 & 39 & 100 & 0 & 35.31 \\
\hline
\end{tabular}

BSC: number of blood slides collected; Positive: malaria positive case; Pf: presence of Plasmodium falciparum; \% Pf: percentage of P. falciparum; SPR: slide positive rate (\%); API: annual parasite incidence.

\section{Discussion}

Monitoring malaria endemicity requires clear value data that can measure and define disease burden encountered in the respective study areas. This study was performed to estimate malaria parameters in five different years of malaria incidences to the implementation of malaria control measures. The study showed variations in malaria indicators according to CHC and SC. In the two study sites only $P$. falciparum infections were observed.The earlier survey has highlighted the prevalence of malaria with hyperendemicity in Koraput district [21]. Authors, studied on malaria prevalence in the district, although incidence of malaria has been reported by the District Health Department every year from 1988 to 2008; the annual parasite incidence (API) ranged from 10.1 (1992) to 25.1 (2008) [22]. The prevalence of $P$. falciparum infection as proposed by Bouma and Van der Kaay [23] and the high prevalence of $P$. falciparum infection as reported earlier [24]. Plasmodium falciparum was the predominant malaria parasite identified to be prevalent in the similar proportion in Koraput district, even in early part of 19th Century [21,25]. Similar to the findings of the present study, in Sundargarh district of Odisha State, P. falciparum accounted for $85.0 \%$ of the total malaria cases recorded from January 2001 to December 2003 [26].

In a malaria endemic region of northwestern Orissa, a longitudinal study carried out and results revealed an SPR of $45 \%$ for forested areas, which was significantly higher than that for the non-forested areas (27\%) [27]. Outbreaks of $P$. falciparum were recorded in some PHCs of Mandla/ Jabalpur and foci of the disease shift spatially virtually from year to year [28].The Orissa state on the east coast of India is endemic for malaria for decades [2]. The state with a population of $3.6 \%$, contributes about $22 \%$ of all malaria cases, $43 \%$ of the Plasmodium falciparum cases and $33 \%$ of total malaria related deaths in the country. Out of 30 districts in Orissa 27 are endemic for malaria and the average annual parasite incidence (API) for the state is 18.6 (+ 13.7). The Koraput district has an average API of 20.3. Transmission of malaria is perennial in all hilltop and foothill villages [21]. In the background of prevailing malaria situations priority interventions with modern technologies are required [29].

The National Vector Borne Disease Control Programme (NVBDCP) epidemiological data for 2010 from the predominantly tribal States with persistent malaria transmission show high API, slide positivity rate (SPR) and very high Pf\%. viz., Odisha, Chhattisgarh, Jharkhand and Madhya Pradesh [30]. The estimates of malaria mortality show " 205,000 malaria deaths per year in India before age $70 \mathrm{yr}$ (55 000 in early childhood, 30000 at ages 5-14 yr, 120000 at ages 15-69 yr); 1.8 per cent cumulative probability of death from malaria before age
70 yr” [31]. Sarakar [32] estimated approximately 180 million malaria cases, half of these $P$. falciaprum. Malaria SPRs, with 95\% confidence interval, across the three ecotypes, hilltop, foothill and plain villages were $27.63 \%$ (30.4-24.85\%), $17.88 \%$ (18.79-16.97\%) and $11.57 \%$ (12.53-10.61\%), respectively. There was a significant $(\chi 2$ $=174.5 ; \mathrm{P}=0.000)$ variation in SPRs between the three ecotypes. However, there was no significant $(\chi 2=14.82$; $\mathrm{df}=8 ; \mathrm{P}=0.063)$ variation in malaria parasite species distribution between the ecotypes [20]. In fact epidemic malaria has unique behavior that requires specialized interventions. Transmission in epidemic-prone areas is usually interrupted by long periods of absence of vectors and parasites, which renders human populations particularly vulnerable to severe disease.

\section{Conclusion}

The present epidemiological data are necessary to develop appropriate malaria control strategies and public health strategy. This study shows that despite an increase of malaria cases observed in endemic area of Koraput district, Odisha State, there is an increased risk of malaria infection in all the reported year in concern District. The malaria epidemiology in Koraput underlines the need to increase, to maintain the various malaria control strategies and to implement on a constant basis, particularly in tribal areas where a recuperate in malaria is being practical. This work has important implications for the planning of future campaign and the introduction of alternating preventive treatment for the tribal community in Koraput district.

\section{Acknowledgement}

The authors are thankful to the District Health Department Officer, CHC and SC staff members and accredited social health activists (ASHAs) workers for their assistance.

\section{Abbreviations}

ABER: Annual Blood examination Rate; EMCP: Enhanced Malaria Control Project; CHC: Community Health Centre; SC: Sub-Centre; SPR: Slide Positivity Rate; API: Annual Parasite incidence; Pf \%: P. falciparum percentage ; NVBDCP: National Vector Borne Disease Control Programme;

\section{References}

[1] Pattanayak S, Sharma VP, Kalra NL, Orlov VS, Sharma RS. Malaria paradigms in India and control strategies. Indian $\mathrm{J}$ Malariol. 1994; 31: 141. 
[2] Rajagopalan PK, Das PK. Problems of malaria control in tribal areas. ICMR Bull 1990; 20(5): 41-6.

[3] National Vector Borne Disease Control Programme: Operational manual for implementation of malaria programme. New Delhi: NVBDCP, Directorate General of Health Services, Ministry of Health and Family Welfare, Government of India; 2009.

[4] Rajagopalan PK, Das PK, Pani SP, Jambulingam P, Mohapatra SSS, Gunasekaran K, Das LK. Parasitological aspects of malaria persistence in Koraput district, Orissa, India. Indian J Med Res 1990; 91(A): 44-51.

[5] Sharma VP. Malaria and poverty in India. Curr Sci. 2003; 84: 513515.

[6] Rajagopalan PK, Pani SP, Das PK, Jambulingam P: Malaria in Koraput district of Orissa. Indian J Pediatr. 1989; 56: 355-364.

[7] Hay SI. The global distribution and population at risk of malaria: past, present and future, Lancet.2004; 4: 327-336.

[8] Webb JLA. A global history of malaria, Cambridge University Press, New York, USA; 2009.

[9] Panigrahi BK, Kerketta AS, Mohapatra A, Hazra RK, Parida SK, Marai NS, Kar SK, Mahapatra N. Effect of construction of an irrigation canal on malaria situation in two primary health centres of Dhenkanal district of Orissa, India. Tropical Biomedicine.2011; 28(1): 76-84.

[10] Herris VK, Richard VS, Mathai E, Sitaram U, Kumar KV, Cherian AM, Amelia SM, Anand G. A study on clinical profile of falciparum malaria in a tertiary care hospital in south India. Indian J Malariol. 2001; 38: 19-24.

[11] BK, Kalyansundaram M. Effect of permethrin impregnated bed nets in reducing population of malaria vector Anopheles culicifacies in a tribal village of Orissa state (India). Indian J Med Res. 1989; 89: 48-51.

[12] Sharma VP, Yadav RS. Impregnating mosquito nets with 8. cyfluthrin. Study in the mining settlements of Orissa, India to control Malaria. Public Health. 1995; 12: 8-17.

[13] Jana-Kara BR, Wajihullah, Shahi B, Dev V, Curtis CF, Sharma VP. Deltamethrin impregnated bed nets against Anopheles minimus transmitted malaria in Assam, India. J Trop Med Hyg. 1995; 98: 73-83.

[14] Prakash A, Bhattacharyya DR, Mohapatra PK, Barua A, Phukan A, Mahanta J. Malaria control in a forest camp in an oil exploration area of upper Assam. Natl Med J India. 2003; 16: 135-8.

[15] Annual Action Plan 2001- 2002. Directorate of Health Services, Chhattisgarh, Raipur.

[16] Malaria Epidemiological Situation 2002. Directorate of National Anti-Malaria Programme, Delhi, 2002.

[17] Singh N, Mehra RK, Sharma VP. Malaria and the Narmada river development in India: A case study of the Bargi dam. Ann Trop Med Parasitol.199; 93: 465-477.
[18] Singh N, Mishra AK, Shukla MM, Chand SK. Forest malaria in Chhindwara, Madhya Pradesh (Central India). A case study in ethnic tribal community. Am J Trop Med Hyg. 2003; 68: 602-612.

[19] Directorate of Economics and Statistics: District Statistical Handbook, Koraput. Bhubaneswar: Directorate of Economics and Statistics, Government of Orissa; 2007.

[20] Sahu SS, Gunasekaran K, Vanamail P, Jambulingam P. Persistent foci of falciparum malaria among tribes over two decades in Koraput district of Odisha State, India. Malaria Journal. 2013; 12: 72-79.

[21] Rajagopalan PK, Das PK, Pani SP, Jambulingam P, Mohapatro SSS, Gunasekaran K, Das LK: Parasitological aspects of malaria persistence in Koraput district, Orissa, India. Indian J Med Res. 1990; 91(A): 44-51.

[22] Office of the Chief District Medical Officer: Annual Report. Koraput: Chief District Medical Office; 2008.

[23] Bouma MJ, Van der Kaay HJ. The EL Nino southern oscillation and the historic malaria epidemics on the Indian subcontinent and Sri Lanka; an early warning system for future epidemics? Tropical Medicine and International Health. 1994; 1: 86-96.

[24] Singh N, Sharma VP.Patterns of rainfall and malaria in Madhya Pradesh, central India. Annals of Tropical Medicine and Parasitology. 2002; 96: 349-359.

[25] Perry EL. Endemic malaria of the jeypore hill tracts of the madras presidency. Indian J Med Res. 1914; 2: 456-491.

[26] Sharma SK, Tyagi PK, Pradhan K, Upadhyay AK, Haque MA, Nanda N, Joshi H, Biswas S, Adak T, Das BS, Chauvan VS, Chitnis CE, Subbarao SK. Epidemiology of malaria transmission in forest and plain ecotype villages in Sundargarh district, Orissa, India. Trans R Soc Trop Med Hyg. 2006; 100: 917-925.

[27] Nanda N, Joshi H, Subbarao SK, Yadav RS, Shukla RP, Dua VK, Sharma VP. Anopheles fluviatilis complex: host feeding patterns of species S, T, and U. J Am Mosq Control Assoc. 1996; 12: 147149.

[28] Singh N, Sharma VP, Shukla MM, Gyanchand S. Malaria outbreak in Kundam block, district Jabalpur (MP). Indian Journal of Malariology.1988; 25: 41-49.

[29] Yadav RS, Bhatt RM, Kohli VK, Sharma VP. The burden of malaria in Ahmedabad city, India - a retrospective analysis of reported cases and deaths. Ann Trop Med Parasitol. 2003; 97: 793-802.

[30] National Vector Borne Disease Control Programme, 16. Directorate General of Health Services, Ministry of Health and Family Welfare, Government of India, Delhi. Available from: http://nvbdcp.gov.in/, accessed on January 14, 2012.

[31] N, Jha P, Sharma VP, Cohen AA, Jotkar RM, Rodriguez PS, et al. Adult and child malaria mortality in India: a nationally representative mortality survey. Lancet. 2010; 376: 1768-74.

[32] Sarkar J. Malaria in pregnancy. 39. Curr Sci. 2012; $103: 15$. 